\title{
Neurological Disease Surveillance in Cameroon, a Rural and Urban-Based Inout Patient Population Study
}

\author{
Jacques Doumbe ${ }^{1, ~}$, Yacouba Njankouo Mapoure ${ }^{1}$, Theophile Nyinyikua ${ }^{1}$, Callixte Kuate ${ }^{1}$, \\ Katie Kompoliti ${ }^{2}$, Hiral Shal ${ }^{3}$, Bichum Ouyang ${ }^{2}$, Sara Calvo ${ }^{4}$, Abel Fernandez-Sierra ${ }^{4}$, \\ Esther $\mathrm{Cubo}^{4}$
}

${ }^{1}$ Department of Neurology, University of Douala, Douala, Cameroon

${ }^{2}$ Department of Neurology, Rush University Medical Center, Chicago, United States

${ }^{3}$ Department of Neurology, Columbia University, New York, NewYork, United States

${ }^{4}$ Department of Neurology, University of Burgos, Burgos, Spain

Email address:

dojana2003@yahoo.fr(J. Doumbe)

*Corresponding author

\section{To cite this article:}

Jacques Doumbe, Yacouba Njankouo Mapoure, Theophile Nyinyikua, Callixte Kuate, Katie Kompoliti, Hiral Shal, Bichum Ouyang, Sara Calvo, Abel Fernandez-Sierra, Esther Cubo. Neurological Disease Surveillance in Cameroon, a Rural and Urban-Based Inout Patient Population Study. Clinical Neurology and Neuroscience. Vol. 3, No. 1, 2019, pp. 24-30. doi: 10.11648/j.cnn.20190301.15

Received: March 17, 2019; Accepted: April 17, 2019; Published: May 31, 2019

\begin{abstract}
Background: There is a paucity of literature on the burden of neurological diseases in sub-Saharan Africa. Objective: To create a registry and surveillance of neurological diseases from urban and rural health centers in Cameroon. Methods: Retrospective review of medical records of inpatients and outpatients from two urban public hospitals in Douala and two rural health care centers, from 2013 to 2015 was conducted. In the urban areas, the diagnosis was made by a neurologist but this was not the case in the rural areas. The following variables were analyzed: demographics, medical center characteristics, presenting neurological complaint, medical history, neurological diagnosis, death and disability. Neurological diseases were classified according to ICD-10. Results: Out of 20,131 medical charts available (13\% from the rural area), 4,187 cases $(20.7 \%)$ with neurological complaints were identified and reviewed, mean age $48.67+18.62$ years, females $54.7 \%$, 188 children (4.4\%). The most frequent neurological complaints were: paresis/weakness (G.82, 25.2\%) and headache (R.51, 22.0\%). The most common concurrent medical history was hypertension (I10, 40.0\%), and HIV (B20, 16.45\%). The most common neurological diagnoses were cerebrovascular disease (G45, G46, 51.5\%), and infection (B50, G00, G04, G06, $24.13 \%$ ) in adults, and epilepsy (G40,64.0\%) in children. Death due to neurological cause was recorded in 428 patients (19.1\%), and disability in 1,072 (57.2\%). Neurodegenerative diseases were exclusively diagnosed in urban areas. Conclusion: Population aging and changes in the distribution of risk factors have accelerated the prevalence of non-communicable diseases such as cerebrovascular disease. However, additional work to characterize the nature of diagnosis, treatment and care is important to advance quality of care in the adult and pediatric neurological disorders. A health policy geared towards prevention and neurological training for health professionals is warranted.
\end{abstract}

Keywords: Neurological Disease, Surveillance, Cameroon

\section{Introduction}

Over the past 25 years, the burden of neurological disorders has increased substantially and at the present time represents the leading cause group of disability, and the second-leading cause group of mortality worldwide. [1] However, despite the high prevalence and disease burden of neurological disorders, [2] most Sub-Saharan countries have less than one neurologist per one million people and lack medically trained personnel. Furthermore, over the last decades, population aging and changes in the distribution of risk factors have accelerated an epidemic of noncommunicable diseases in many developing countries. [2, 3] In this regard, in developing countries the burden of 
neurological diseases, especially neurodegenerative diseases, results from being both under-recognized and under-treated. $[4,5]$ Much recent neuro-epidemiological work in Africa has been carried out in urban areas, [6] but data regarding disability and death associated with neurological diseases is still scarce, especially for non-communicable diseases in the rural areas. $[7,8]$

Epidemiology plays an important role in elucidating patterns in the occurrence of disease and determining risk factors and etiology. $[9,10]$ While obtaining information on the burden of neurological diseases by region or district is important so that interventions can be specifically targeted, there is also a need to establish a reliable database system to record the prevalence of neurological diseases in larger geographical areas like the Sub-Saharan African countries.

Cameroon is located in Central Africa with a population of over 22 million people (World Bank 2013) and life expectancy 54.59 years (World Bank 2012). It has been identified by the World Health Organization (WHO) as having critical shortage of health care workers and geographic distributional inequalities that are even more severe in rural areas. [11] Although there is a small body of literature on the hospital-based prevalence of neurological disorders in Cameroon, [12, 5] little is known about the prevalence of neurological disorders in the rural area. To address this lack of information, we conducted a collaborative project in Cameroon to create a registry and surveillance of neurological disorders including neurodevelopmental disorders, stroke, epilepsy, neurodegenerative diseases, neuromuscular diseases and central nervous system infections. Our objective was to provide reliable data of neurological disease surveillance in the context of the selected urban hospitals and rural clinics, thus encompassing both urban and rural areas.

\section{Methods}

Design: Retrospective chart review of neurological cases with a primary neurological complaint being the main reason for admission to the hospital/visit to the outpatient clinic, seen either in an inpatient setting in 2 urban public hospitals in Douala (Laquintinie hospital and General Hospital) or in an outpatient setting in 2 rural health care centers (Tiko and Mbouda), in Cameroon, from May $1^{\text {st }} 2013$ to May $1^{\text {st }} 2015$.

Start-up \& Ethics: The investigators (EC and KK) travelled to Laquintinie Hospital, Douala, Cameroon in 2014, to invite physicians to participate in the registry of neurological diseases. During an one-day course, the basis of the neurological diseases registry, project methodology and local networks between neurologists and primary care doctors were discussed. A local neurologist (JD) was designated as the principal investigator in Cameroon. This project was approved by the Internal Review Board (IRB) at Douala Laquintinie Hospital (Cameroon) and at the principal investigator IRB (Hospital Universitario Burgos, Spain).

Procedure: The in/outpatient settings covered an urban population of 3,000,000 inhabitants served by 9 neurologists in 2 hospitals (Douala and Yaoundé), and a rural population of 380, 276 inhabitants served by 20 doctors, mainly primary care. A senior medical student from Douala University Medical School was engaged (TN) to be the primary data collector for this project. Regular teleconferences between the investigators were performed to discuss data collection and analysis issues. All medical centers provided a registry of patients with neurological complaints (paper datasheet), and each individual medical chart of patients with neurological complaints was reviewed by the primary data collector. To avoid duplicity, each patient was accounted once with the primary neurological complaint.

Outcomes: Clinical, and socio demographic information was obtained from the medical charts. Neurological diagnosed were performed by 9 neurologists in the overwhelming majority of cases in the urban areas, and by internists, general practitioners and other medical specialties in the rural areas. Medical history, neurological complaints, and neurological disorders were coded according to the International Statistical Classification of Diseases-Related Health Problems 10th revision (ICD-10) by the primary data collector.[13] The following data were collected from the patients' records: age, sex, profession, residence (rural vs. urban), the main neurological complaint upon consultation/admission, medical history (tobacco and alcohol exposure, presence of arterial hypertension, diabetes mellitus, dyslipidemia, HIV infection and malaria), district population, number of neurologists, access to laboratory services, including microbiological testing, and Computerized Tomography scan, disability (ranging from independence to partial/full dependence, based on the medical chart notes and investigator criteria), and death. Pediatric cases were classified as infants (0-2 years), toddlers (3-6 years) and children/teenagers ( $7-16$ years).

Internal validity of neurological diagnosis. Training for entered data accuracy in the database was established by comparing the ICD-10 codes based on the clinical information obtained from the medical chart, and entered in the database by the local neurologist (JD) from 11 medical charts (as the gold standard), to the ICD-10 codes entered in the database by the primary data collector. To certify the data collector, an inter-rater agreement with a Kappa coefficient $>$ 0.8 was necessary. The inter-rater agreement was low in the first round (kappa coefficient of 0.5), but high in the second round (kappa coefficient of 0.9) using 11 different medical charts.

To establish the accuracy of neurological diagnoses provided by non-neurologist medical doctors involved in the care of the patients included in this registry, a clinical test including the clinical vignettes of 10 general neurology cases was conducted. Three internists from the urban medical centers, and 4 primary care doctors from the rural medical centers, completed the clinical test. There were a mean number of $8.6+0.5$ correct answers from physicians in urban centers, and $7.4+0.8$ in rural centers.

Statistical analysis: Statistical analyses were performed using SPSS Version 21.0 (SPSS, Inc., Chicago, IL). 
Descriptive statistics [i.e. means + standard deviations, range and $95 \%$ confidence intervals (CI) based on the Poisson distribution] were used to describe the demographic and clinical data. Death rate was calculated in the inpatient sample and disability was assessed in the survivors of the inpatient sample.

\section{Results}

From May $1^{\text {st }} 2013$ to May $1^{\text {st }} 2015,20,131$ medical charts of patients seeking care either in the two hospitals in Douala or the outpatient clinics in Tiko and Mbouda, were available ( $13 \%$ from the rural areas). In this review 4,187 cases with neurological complaints as the main problem resulting in admission/visit were identified and reviewed (20.8\% of all cases). Of those cases with primary neurological complaints, 3,976 cases were diagnosed by neurologists $(94.9 \%)$ [2,234 $(53.3 \%)$ were inpatients $(89,7 \%$ from the urban area, and $10.3 \%$ from the rural area); $1,945(46.4 \%)$ were outpatients $(100 \%$ from the urban area)]. There were 188 pediatric cases (4.4\%), of thoses $180(95.7 \%)$ were from the urban area.

Overall, the most frequent neurological complaints were paresis/weakness (G.82, 25.2\%) and headache (R.51, 22.0\%) The most common concurrent medical history was hypertension (I10, 32.2\%), and HIV (B20, 13.5\%). The socio-demographic and leading diagnosis characteristics of this cohort of patients are depicted in table 1. The overwhelming majority (both urban and rural cases) had access to CT (89.89\%), microbiology laboratory (89.89\%), or general laboratory $(100 \%)$ for diagnostic purposes.

The Leading diagnosis, medical history, disability and deaths in adults, both rural and urban cases are illustrated in Table 2. Overall, cerebrovascular disease (G45, G46) was diagnosed in 1338 patients (34\%), was associated to disability in 651 patients $(76 \%)$ and caused death in 239 patients $(21 \%)$. The most frequent diagnoses in the outpatient cohort were upper and lower limb mononeuritis (G56, G57) in 611 patients $(15 \%)$. In the pediatric group (Table 3 ), the most frequent diagnosis was epilepsy (G40) in 120 cases (64\%). Neurodegenerative diseases such as Parkinson's disease, secondary Parkinsonism, Alzheimer disease and other dementias (G20, G21, G30, G31) were diagnosed in 160 cases $(4.0 \%)$, exclusively from urban centers. Death was reported in 428 (26.4\%), 425 adults (19.4\%) and 3 children $(7 \%)$. The diseases resulting in the greatest mortality were cerebrovascular disease (55.3\%), CNS infection (36.4\%),
CNS tumor (3.8\%), and epilepsy (2.4\%). Disability data was exclusively available from urban cases. Among the 1803 survivors, dependence was observed in 810 patients $(44.9 \%)$, $361(44.5 \%)$ patients had mild-moderate dependence (need for help with Activities of Daily Life-dressing, feeding, bathing-but could do most things by themselves), and 275 patients $(33.9 \%)$ patients were fully dependent.

Table 1. Demographics and medical history characteristics in Urban vs. Rural patients.

\begin{tabular}{|c|c|c|}
\hline Frequency (\%) & Urban $N=3955$ & Rural N=231 \\
\hline \multicolumn{3}{|l|}{ Gender } \\
\hline Female & $2157(54.5)$ & $134(58.3)$ \\
\hline Missing information & $3(0.1)$ & $1(0.4)$ \\
\hline \multicolumn{3}{|l|}{ Marital status } \\
\hline Married & $1531(38.7)$ & $173(74.9)$ \\
\hline Widowed & $345(8.7)$ & $29(12.6)$ \\
\hline Missing information & $1278(32.3)$ & $0(0)$ \\
\hline \multicolumn{3}{|l|}{ Working status } \\
\hline Active worker & $1833(46.3)$ & $16(6.9)$ \\
\hline Retired due to age & $389(9.8)$ & $2(0.9)$ \\
\hline Housewife & $890(22.5)$ & $4(1.7)$ \\
\hline Unemployed & $605(15.3)$ & $4(1.7)$ \\
\hline Missing information & $238(6)$ & $205(88.7)$ \\
\hline \multicolumn{3}{|l|}{ Education } \\
\hline Illiteracy, low level & $1741(44.0)$ & - \\
\hline Middle-high school & $939(23.7)$ & $1(0.4)$ \\
\hline University & $595(15.0)$ & - \\
\hline Missing information & $680(17.2)$ & $230(99.6)$ \\
\hline \multicolumn{3}{|l|}{ Disability } \\
\hline Yes & $1052(26.2)$ & $21(4.1)$ \\
\hline Missing information & $2146(54.3)$ & $163(70.6)$ \\
\hline \multicolumn{3}{|l|}{ Death } \\
\hline Yes & $385(9.7)$ & $43(18.6)$ \\
\hline Missing information & $2146(54.3)$ & 0 \\
\hline \multicolumn{3}{|l|}{ Leading Diagnosis* } \\
\hline Cerebrovascular disease & $1254(31.9)$ & $89(39.3)$ \\
\hline Mononeuritis & $616(15.6)$ & $17(7.5)$ \\
\hline Epilepsy & $544(13.8)$ & $18(8.0)$ \\
\hline Headache & $501(12.7)$ & $5(2.2)$ \\
\hline Infection & $478(12.1)$ & $62(27.4)$ \\
\hline Tumor & $126(3.2)$ & $5(2.2)$ \\
\hline
\end{tabular}

*Diagnosis frequency (\%) is established based on available data. Cerebrovascular disease includes the ICD-10 codes G45,G46; Mononeuritis includes the ICD-10 codes G56,G57; Infection includes the ICD-10 codes B50,B99,G00,G04;G06; Headache includes the ICD-10 code G43; Epilepsy include the ICD-10 code G40; Tumor include the ICD-10 codes.

Table 2. Leading diagnosis, medical history, disability and deaths in adults.

\begin{tabular}{|c|c|c|c|c|c|c|c|c|c|c|c|c|}
\hline \multirow{2}{*}{$\begin{array}{l}\text { Diagnosis } \\
\text { Disease }\end{array}$} & \multicolumn{6}{|c|}{ Medical history } & \multicolumn{3}{|c|}{ Disability (yes) } & \multicolumn{3}{|c|}{ Death (yes) } \\
\hline & $\begin{array}{l}\text { Total } \\
\text { sample }\end{array}$ & Frequency & Total sample & $\begin{array}{l}\text { ICD-10 } \\
\text { code }\end{array}$ & $\mathbf{n}$ & Frequency & $\begin{array}{l}\text { Total } \\
\text { sample }\end{array}$ & $\mathbf{n}$ & Frequency & $\begin{array}{l}\text { Total } \\
\text { sample }\end{array}$ & $\mathbf{n}$ & Frequency \\
\hline $\begin{array}{l}\text { Cerebrovas. } \\
\text { disease }\end{array}$ & 1338 & $34 \%$ & 1286 & $\begin{array}{l}\text { I10 } \\
\text { E11 } \\
\text { F10 } \\
\text { G45.1 } \\
\text { I21 } \\
\text { F17 } \\
\text { B20 } \\
\text { E78 }\end{array}$ & $\begin{array}{l}825 \\
204 \\
164 \\
123 \\
109 \\
88 \\
38 \\
34 \\
\end{array}$ & $\begin{array}{l}64 \% \\
16 \% \\
13 \% \\
10 \% \\
8 \% \\
7 \% \\
3 \% \\
3 \% \\
\end{array}$ & 851 & 651 & $76 \%$ & 1151 & 239 & $21 \%$ \\
\hline
\end{tabular}




\begin{tabular}{|c|c|c|c|c|c|c|c|c|c|c|c|c|}
\hline \multicolumn{3}{|l|}{ Diagnosis } & \multicolumn{4}{|c|}{ Medical history } & \multicolumn{3}{|c|}{ Disability (yes) } & \multicolumn{3}{|c|}{ Death (yes) } \\
\hline Disease & $\begin{array}{l}\text { Total } \\
\text { sample }\end{array}$ & Frequency & Total sample & $\begin{array}{l}\text { ICD-10 } \\
\text { code }\end{array}$ & $\mathbf{n}$ & Frequency & $\begin{array}{l}\text { Total } \\
\text { sample }\end{array}$ & $\mathbf{n}$ & Frequency & $\begin{array}{l}\text { Total } \\
\text { sample }\end{array}$ & $\mathbf{n}$ & Frequency \\
\hline \multirow{13}{*}{$\begin{array}{l}\text { Mononeuriti } \\
\text { s }\end{array}$} & \multirow{13}{*}{611} & \multirow{13}{*}{$15 \%$} & \multirow{13}{*}{525} & A15 & 11 & $1 \%$ & \multirow{13}{*}{48} & \multirow{13}{*}{1} & \multirow{13}{*}{$2 \%$} & \multirow{13}{*}{63} & \multirow{13}{*}{3} & \multirow{13}{*}{$5 \%$} \\
\hline & & & & G40.1 & 5 & $0 \%$ & & & & & & \\
\hline & & & & A16 & 1 & $0 \%$ & & & & & & \\
\hline & & & & $\mathrm{I} 10$ & 94 & $18 \%$ & & & & & & \\
\hline & & & & F10 & 29 & $6 \%$ & & & & & & \\
\hline & & & & E11 & 26 & $5 \%$ & & & & & & \\
\hline & & & & F17 & 9 & $2 \%$ & & & & & & \\
\hline & & & & G45.1 & 9 & $2 \%$ & & & & & & \\
\hline & & & & B20 & 6 & $1 \%$ & & & & & & \\
\hline & & & & E78 & 3 & $1 \%$ & & & & & & \\
\hline & & & & A15 & 2 & $0 \%$ & & & & & & \\
\hline & & & & $\mathrm{F} 12$ & 1 & $0 \%$ & & & & & & \\
\hline & & & & $\mathrm{I} 21$ & 1 & $0 \%$ & & & & & & \\
\hline \multirow{12}{*}{ Infection } & \multirow{12}{*}{601} & \multirow{12}{*}{$15 \%$} & & B20 & 350 & $59 \%$ & & & & & & \\
\hline & & & & I10 & 51 & $9 \%$ & & & & & & \\
\hline & & & & A15 & 42 & $7 \%$ & & & & & & \\
\hline & & & & F10 & 31 & $5 \%$ & & & & & & \\
\hline & & & & E11 & 22 & $4 \%$ & & & & & & \\
\hline & & & 598 & F17 & 17 & $3 \%$ & & & & & 152 & \\
\hline & & & 598 & G45.1 & 7 & $1 \%$ & 460 & 105 & $23 \%$ & 535 & 152 & $28 \%$ \\
\hline & & & & G40.1 & 5 & $1 \%$ & & & & & & \\
\hline & & & & F12 & 3 & $1 \%$ & & & & & & \\
\hline & & & & E78 & 2 & $0 \%$ & & & & & & \\
\hline & & & & B21 & 1 & $0 \%$ & & & & & & \\
\hline & & & & $\mathrm{I} 21$ & 1 & $0 \%$ & & & & & & \\
\hline & & & & $\mathrm{I} 10$ & 37 & $11 \%$ & & & & & & \\
\hline & & & & F10 & 15 & $4 \%$ & & & & & & \\
\hline & & & & E11 & 10 & $3 \%$ & & & & & & \\
\hline & & & & F17 & 9 & $3 \%$ & & & & & & \\
\hline Headache & 494 & $12 \%$ & 351 & B20 & 6 & $2 \%$ & 42 & 0 & $0 \%$ & 46 & 1 & $2 \%$ \\
\hline & & & & G45.1 & 5 & $1 \%$ & & & & & & \\
\hline & & & & $\mathrm{I} 21$ & 2 & $1 \%$ & & & & & & \\
\hline & & & & E78 & 1 & $0 \%$ & & & & & & \\
\hline & & & & $\mathrm{I} 10$ & 102 & $26 \%$ & & & & & & \\
\hline & & & & G45.1 & 51 & $13 \%$ & & & & & & \\
\hline & & & & G40.1 & 37 & $9 \%$ & & & & & & \\
\hline & & & & F10 & 22 & $6 \%$ & & & & & & \\
\hline & 442 & $11 \%$ & & E11 & 20 & $5 \%$ & 217 & 37 & $17 \%$ & 239 & 17 & $7 \%$ \\
\hline Epilepsy & 442 & $11 \%$ & 397 & B20 & 16 & $4 \%$ & 217 & 37 & $17 \%$ & 239 & 17 & $7 \%$ \\
\hline & & & & F17 & 12 & $3 \%$ & & & & & & \\
\hline & & & & $\mathrm{I} 21$ & 5 & $1 \%$ & & & & & & \\
\hline & & & & A15 & 4 & $1 \%$ & & & & & & \\
\hline & & & & E78 & 4 & $1 \%$ & & & & & & \\
\hline & & & & $\mathrm{I} 10$ & 19 & $16 \%$ & & & & & & \\
\hline & & & & F10 & 11 & $9 \%$ & & & & & & \\
\hline & & & & B20 & 8 & $7 \%$ & & & & & & \\
\hline Tumor & 125 & $3 \%$ & 120 & E11 & 8 & $7 \%$ & 80 & 36 & $45 \%$ & 85 & 16 & $19 \%$ \\
\hline & & & & F17 & 7 & $6 \%$ & & & & & & \\
\hline & & & & A15 & 3 & $3 \%$ & & & & & & \\
\hline & & & & G45.1 & 1 & $1 \%$ & & & & & & \\
\hline
\end{tabular}

Overall data was available in 3992/3998 (99.8\%). Medical history was available in 3151/3955 (79.5\%) urban cases, and 103/231 (44.5\%) rural cases. Cerebrovasc. Disease (Cerebrovascular disease) includes the ICD-10 codes G45,G46; Mononeuritis include the ICD-10 codes G56,G57; Infection includes the ICD-10 codes B50,B99,G00,G04;G06; Headache includes the ICD-10 code G43; Epilepsy include the ICD-10 code G40; Tumor include the ICD-10 codes. Medical history include the ICD-10 codes: I10 Arteial hypertension; F83 birth injury; B20,B21 Human immunodeficiency virus; A15,A16,A17 Tuberculosis; B50 Malaria; F17 Tobacco, F10 Alcohol, F12, F14 other drugs, E10,E11 Diabetes Mellitus; E78 Dyslipemia, I21 Ischemic cardiac disease.

Table 3. Leading pediatric neurological complaints and diagnosis.

\begin{tabular}{lllll}
\hline $\mathbf{N}(\%)$ & Total sample N=188 & Infant 0-2 years $\mathbf{N}=\mathbf{1 3}$ & Toddler 3-6 years $\mathbf{N = 3 8}$ & Children 7-16 years N=137 \\
\hline Female & $104(55)$ & $6(46)$ & $21(55)$ & $77(56)$ \\
$\begin{array}{l}\text { Outpatient } \\
\text { Location }\end{array}$ & $145(77)$ & $11(85)$ & $38(100)$ & $96(70)$ \\
Urban & $180(96)$ & $13(100)$ & $38(100)$ & $129(94)$ \\
Rural & $8(4)$ & $0(0)$ & $0(0)$ & $8(6)$ \\
Primary Neurological complaint & & & & \\
\hline
\end{tabular}




\begin{tabular}{|c|c|c|c|c|}
\hline $\mathbf{N}(\%)$ & Total sample $\mathrm{N}=188$ & Infant $0-2$ years $N=13$ & Toddler 3-6 years $N=38$ & Children $7-16$ years $\mathrm{N}=137$ \\
\hline Fever of unknown origin & $18(13)$ & $1(8)$ & $1(3)$ & $16(16)$ \\
\hline Seizure & $73(50)$ & $4(33)$ & $19(63)$ & $50(49)$ \\
\hline Headache & $40(27)$ & $1(8)$ & $4(13)$ & $35(34)$ \\
\hline Mental status change & $38(26)$ & $1(8)$ & $2(7)$ & $35(34)$ \\
\hline \multicolumn{5}{|l|}{ Diagnosis } \\
\hline Epilepsy & $120(64)$ & $5(42)$ & $33(87)$ & $82(60)$ \\
\hline Headache & $12(6)$ & $0(0)$ & $0(0)$ & $12(9)$ \\
\hline Cerebral palsy unspecified & $9(5)$ & $4(31)$ & $1(3)$ & $4(3)$ \\
\hline Infection & $10(19)$ & $2(17)$ & $3(8)$ & $5(4)$ \\
\hline Tumor & $7(4)$ & $0(0)$ & $1(3)$ & $5(4)$ \\
\hline Tremor/Myoclonus & $5(3)$ & $1(8)$ & $0(0)$ & $4(3)$ \\
\hline
\end{tabular}

Epilepsy includes the ICD-10 code G40; Fever of unknown origin include the ICD-10 code R50; Seizure the ICD-10 code R56; Headache the ICD-10 code R51, and Mental status change the ICD-10 code R40; Headache includes the ICD-10 code G43; Cerebral palsy include the ICD-10 code G80.9; Infection include the ICD-10 codes G00, G04; Tumor includes the ICD-10 codes C70,C71,C72; Tremor/Myoclonus includes the ICD-10 code G25.

\section{Discussion}

Our study is one of the largest retrospective reviews measuring the frequency of all serious neurological conditions, requiring either an outpatient visit or hospitalization in urban and rural areas of Sub Saharan Africa, including pediatric and adult cases. The most common diagnoses in both the inpatient and the outpatient samples were, similar to other studies involving Cameroon, with non-infectious neurological diseases being more common than infectious diseases. [8, 14, 15] In our sample we found that the major neurological disease resulting in hospitalization was cerebrovascular disease, accounting for a little more than half the cases, followed by CNS infections, accounting for almost a quarter of the cases. Among admissions for neurological reasons, $19.0 \%$ resulted in death and among the survivors, $44.5 \%$ of patients were mildly to moderately dependent and $33.9 \%$ were fully dependent. Interestingly, we have previously published a separate analysis for disability and death, and found that higher educational level was associated with decreased likelihood of disability. [16] To explain this finding several hypotheses can be taken into account such as the fact that higher educational level is usually associated with higher socioeconomic status and healthier life style, which may lead to a decrease cerebrovascular risk factors, or earlier recognition of stroke symptomatology and thus earlier intervention. However, this information cannot be extrapolated to the overall community due to selection bias with a large proportion of disability missing data especially from the rural area, lack of information regarding long-term disability, and the limited reliability of the operative definition for disability used in this study.

Traditionally, the neurological complications of infectious diseases (HIV infection, tuberculosis and malaria) have been considered to account for a significant portion of the neurological diseases found in the countries of Sub Saharan Africa.[17-19] Contrary to this belief, cerebrovascular disease accounted for $51.0 \%$ of neurological admissions in this urban sample, $55.3 \%$ of the neurological mortality and $79.7 \%$ of the neurological disability among the survivors. Other studies in Sub-Saharan Africa have reported crude yearly stroke incidence rates of 94.5-107.9/100,000, associated with high mortality rates. [20, 21] Therefore, cerebrovascular disease represents the leading cause of mortality and disability. Cerebrovascular disease though, in the ICD-10 classification has been classified with the cardiovascular diseases in the chapter on circulatory disorders. This anomaly has made statistics on neurologic mortality and morbidity misleading. [22] A detailed analysis about the neurological diseases and risk factors associated with death and disability in this cohort has been published elsewhere. [16].

Overall, the body of literature on neurodegenerative disorders in Sub-Saharan countries is large with regards to dementia and HIV-related neurocognitive disorders, [23] but there is limited data on other neurodegenerative disorders. [24] Our results are in agreement with previous studies conductedin Africa. The prevalence of neurological disorders in those aged 70 years and over in a rural community in Tanzania, was 154.1 per 1000 (95\% CI 139.2-169.1), and the most common neurological disorders were tremor (48.2), headache (41.8), stroke (23.0), peripheral polyneuropathy (18.6), upper limb mononeuropathy (6.5) and parkinsonism (5.9). [8] Moreover, based on recent estimates, it is predicted that by 2050 there will be 139 million people aged 60 and older living in Sub-Saharan Africa, $[25,26]$ with a subsequent increase in the prevalence and burden of neurodegenerative disorders. [25] Kuate et al, [5] also reported that the most frequent complaints and neurological diseases were low back pain (19.7\%), tremor and movement disorders $(13.8 \%)$ and gait disorders $(4.3 \%)$ in a hospitalbased sample in Yaoundé-Cameroon. Of note, neurodegenerative disorders in our sample were exclusively diagnosed in the urban areas, indicating these diseases are likely underdiagnosed and undertreated, especially in the rural areas.

Pediatric patients with neurological disorders were more often diagnosed in urban health care facilities, with the most common complaint being seizure and the most common neurological disorder being epilepsy. Previous work on epilepsy in sub-Saharan Africa has shown that many cases are severe and frequently not adequately treated. $[27,6]$ The prevalence of epilepsy, estimated from door to-door studies in Sub-Saharan countries, is almost double than in Asia, 
Europe and North America. [28] The most commonly cited risk factors for epilepsy are birth trauma, CNS infections, tumors and traumatic brain injury. [29] These were identified up to $6 \%$ in our sample. Additional work to better characterize the nature of diagnosis and treatment in this part of the world is important in order to improve quality of care in this vulnerable population.

The main limitation of our study is that the conclusions apply to a selected in-outpatient sample and cannot be directly compared to population-based studies. Likewise, the frequency estimates obtained from these specific inoutpatient settings can be limited by several factors including selection bias because the majority of patients were inpatients, which skews the data toward stroke and underestimates degenerative diseases and dementia. Moreover, data quality in terms of recognition of neurological complaints of hospital registries, patient's access, type of health care facilities, and doctor's expertise, restricting the extrapolation of our prevalence estimates to the greater community or the whole country. Furthermore, although the accuracy of our data was examined, especially the accuracy of neurological disorders diagnosis established by non-neurologists physicians in a limited sample of doctors involved in the care of this cohort, we do not have data in terms of their specific expertise in highly specialized neurological diseases, resulting likely in diagnosis bias. Moreover, a selection bias due to small representation of the rural population, especially for the pediatric population should be taken into account.

However, despite all of these limitations, due to the lack of epidemiological data in Sub-Saharan countries, this type of publication raises awareness in neurological conditions, especially cerebrovascular disease as the leading cause of mortality and disability in this cohort. Furthermore, the information is especially valuable given that the overwhelming majority of patients in the urban areas were diagnosed by a neurologist. Finally, it is important to note that our registry included adult and pediatric population, both an urban and rural sample, which have been rarely done in previous studies. [5,6] Accurate frequency of neurological conditions is needed to address the effects of the demographic shift that is taking place in many regions of the world, including Sub-Saharan countries to provide.

\section{Conclusion}

There is no doubt, that improving access to patients with neurological disorders must be coupled with increased education to raise awareness of these diseases including diagnosis and treatment, especially in the rural areas. Furthermore, high-quality neurological disorder training for health care providers is essential to tackle this increasing need. Our study findings have important health service implications including adequate planning by governments and other health care providers for prevention and management of neurological conditions.

\section{Authors' Contribution}

1. Research Project: $\mathrm{A}=$ Conception, $\mathrm{B}=$ Organization, $\mathrm{C}=$ Execution

2. Statistical Analysis: $A=$ Design, $B=$ Execution, $C=$ Review and Critique

3. Manuscript Preparation: $A=$ Writing the First Draft, $B=$ Review and Critique.

JD: 1A, 1B, 1C, 2C, 3A, 3B

YNM: 1B, 1C, 2C, 3B

TN: $1 \mathrm{C}, 3 \mathrm{~B}$

$\mathrm{CK}: 1 \mathrm{C}, 2 \mathrm{C}, 3 \mathrm{~B}$

$\mathrm{KK}: 1 \mathrm{~A}, 1 \mathrm{~B}, 2 \mathrm{C}, 3 \mathrm{~B}$

BO: $2 \mathrm{C}, 3 \mathrm{~B}$

HS: $1 \mathrm{~B}, 2 \mathrm{C}, 3 \mathrm{~B}$

$\mathrm{SC}: 2 \mathrm{C}, 3 \mathrm{~B}$

AFS: $2 \mathrm{C}, 3 \mathrm{~B}$

EC: 1A, 1B, 2B, 2C, 3A, 3B

\section{Funding}

This study was funded by the World Federation of Neurology and the International Parkinson's Disease and Movement Disorder Society.

\section{Conflict of Interest}

The authors declare that they have no competing interests.

\section{References}

[1] Group GBDNDC. Global, regional, and national burden of neurological disorders during 1990-2015: a systematic analysis for the Global Burden of Disease Study 2015. Lancet Neurol 2017; 16: 877-897.

[2] Murray CJ, Lopez AD. Measuring the global burden of disease. N Engl J Med 2013; 369: 448-457.

[3] Murray CJ, Vos T, Lozano R, et al. Disability-adjusted life years (DALYs) for 291 diseases and injuries in 21 regions, 1990-2010: a systematic analysis for the Global Burden of Disease Study 2010. Lancet 2012; 380: 2197-2223.

[4] Bower JH, Asmera J, Zebenigus M, Sandroni P, Bower SM, Zenebe G. The burden of inpatient neurologic disease in two Ethiopian hospitals. Neurology 2007; 68: 338-342.

[5] Callixte KT, Clet TB, Jacques D, Faustin Y, Francois DJ, Maturin TT. The pattern of neurological diseases in elderly people in outpatient consultations in Sub-Saharan Africa. BMC Res Notes 2015; 8: 159.

[6] Preux PM, Druet-Cabanac M. Epidemiology and aetiology of epilepsy in sub-Saharan Africa. Lancet Neurol 2005; 4: 21-31.

[7] Mukendi D, Lilo Kalo JR, Mpanya A, et al. Clinical Spectrum, Etiology, and Outcome of Neurological Disorders in the Rural Hospital of Mosango, the Democratic Republic of Congo. Am J Trop Med Hyg 2017; 97: 1454-1460. 
[8] Dewhurst F, Dewhurst MJ, Gray WK, et al. The prevalence of neurological disorders in older people in Tanzania. Acta Neurol Scand 2013; 127: 198-207.

[9] Kurtzke JF. Neuroepidemiology. Ann Neurol 1984; 16: 265277.

[10] Cockerell OC, Sander JW, Shorvon SD. Neuroepidemiology in the United Kingdom. J Neurol Neurosurg Psychiatry 1993; 56: 735-738.

[11] Tandi TE, Cho Y, Akam AJ, et al. Cameroon public health sector: shortage and inequalities in geographic distribution of health personnel. Int J Equity Health 2015; 14: 43.

[12] Tegueu CK, Nguefack S, Doumbe J, Fogang YF, Mbonda PC, Mbonda E. The spectrum of neurological disorders presenting at a neurology clinic in Yaounde, Cameroon. Pan Afr Med J 2013; 14: 148.

[13] http: //www.who.int/classifications/icd/en/GRNBOOK.pdf.

[14] Dewhurst F, Dewhurst MJ, Gray WK, et al. Rates of diagnosis and treatment of neurological disorders within a prevalent population of community-dwelling elderly people in subSaharan Africa. J Epidemiol Glob Health 2012; 2: 207-214.

[15] Akinyemi RO, Izzeldin IM, Dotchin C, et al. Contribution of noncommunicable diseases to medical admissions of elderly adults in Africa: a prospective, cross-sectional study in Nigeria, Sudan, and Tanzania. J Am Geriatr Soc 2014; 62: 1460-1466.

[16] Kompoliti K, Doumbe J, Mapoure YN, et al. Mortality and morbidity among hospitalized adult patients with neurological diseases in Cameroon. J Neurol Sci 2017; 381: 165-168.

[17] Brinkhof MW, Boulle A, Weigel R, et al. Mortality of HIVinfected patients starting antiretroviral therapy in sub-Saharan Africa: comparison with HIV-unrelated mortality. PLoS Med 2009;6:e1000066.

[18] Tsegaw M, Andargie G, Alem G, Tareke M. Screening HIVassociated neurocognitive disorders (HAND) among HIV positive patients attending antiretroviral therapy in South Wollo, Ethiopia. J Psychiatr Res 2017; 85: 37-41.

[19] Marks M, Jarvis JN, Howlett W, Mabey DCW. Neurosyphilis in Africa: A systematic review. PLoS Negl Trop Dis 2017; 11: $\mathrm{e} 0005880$.
[20] Walker R, Whiting D, Unwin N, et al. Stroke incidence in rural and urban Tanzania: a prospective, community-based study. Lancet Neurol 2010;9:786-792.

[21] Tekle-Haimanot R, Abebe M, Gebre-Mariam A, et al. Community-based study of neurological disorders in rural central Ethiopia. Neuroepidemiology 1990; 9: 263-277.

[22] Shakir R, Bergen D. International Classification of Diseases (ICD-11) and neurologic disorders: the future. Neurology 2013; 81: 182-183.

[23] Van Heerden A, Barnabas RV, Norris SA, Micklesfield LK, van Rooyen H, Celum C. High prevalence of HIV and noncommunicable disease (NCD) risk factors in rural KwaZuluNatal, South Africa. J Int AIDS Soc 2017; 20.

[24] Lekoubou A, Echouffo-Tcheugui JB, Kengne AP. Epidemiology of neurodegenerative diseases in sub-Saharan Africa: a systematic review. BMC Public Health 2014; 14: 653.

[25] Dotchin C, Jusabani A, Gray WK, Walker R. Projected numbers of people with movement disorders in the years 2030 and 2050: implications for sub-Saharan Africa, using essential tremor and Parkinson's disease in Tanzania as an example. Mov Disord 2012; 27: 1204-1205; author reply 1207.

[26] Stuck AE, Tenthani L, Egger M. Assessing population aging and disability in sub-Saharan Africa: lessons from Malawi? PLoS Med 2013; 10: e1001441.

[27] Ba-Diop A, Marin B, Druet-Cabanac M, Ngoungou EB, Newton CR, Preux PM. Epidemiology, causes, and treatment of epilepsy in sub-Saharan Africa. Lancet Neurol 2014; 13: 1029-1044.

[28] Ngugi AK, Bottomley C, Kleinschmidt I, et al. Prevalence of active convulsive epilepsy in sub-Saharan Africa and associated risk factors: cross-sectional and case-control studies. Lancet Neurol 2013; 12: 253-263.

[29] Mung'ala-Odera V, White S, Meehan R, et al. Prevalence, incidence and risk factors of epilepsy in older children in rural Kenya. Seizure 2008; 17: 396-404. 